\title{
1924. En la UNAM: establecimiento de la Facultad de Filosofía y Letras. \\ En la filosofía y las letras alemanas: cima y anuncio de un desastre*
}

\author{
Renata VON HANFFSTENGEL \\ Universidad Nacional Autónoma de México
}

La Universidad, entre muchas otras funciones que ejerce, es guardián de la historia, de la cual, por supuesto, ella misma también forma parte. Este hecho constituyó el eje del discurso pronunciado por el maestro emérito Álvaro Matute durante la Ceremonia del Día del Maestro realizada en el Palacio de Minería el 14 de mayo de 2004. ' El maestro Álvaro Matute destacó que, al asumir la Rectoría de la Universidad Nacional de México en junio de 1920, José Vasconcelos empezó a darle el rumbo que iba a ser definitivo para la educación superior en México. Además, observó, fue un acierto dar a la Universidad Nacional el escudo y el lema que aún la identifican. Esto ocurrió aproximadamente a los diez años de su renovada fundación, que se efectuó el 22 de septiembre de 1910.

Una de las primeras facultades en establecerse formalmente en la Universidad Nacional fue la de Filosofía y Letras. Por ende, en la ceremonia aludida, los profesores de esta Facultad fueron los primeros en desfilar para recibir sus reconocimientos por los treinta y cinco o cincuenta años de labor. Después siguieron los profesores de otras facultades y de los institutos de investigación, estos últimos mucho mejor atendidos dentro del presupuesto que la venerable Facultad de Filosofía y Letras, a la que, sin duda alguna, se refería "el espíritu" que hablaría por la raza. Esperemos que la Facultad de Filosofía y Letras haga honor a este lugar de preeminencia dentro de la vasta Universidad Nacional Autónoma de México como hoy la conocemos.

Los cuatro departamentos de la Coordinación de Letras Modernas apenas tienen unos cincuenta años de existencia. En nuestra labor diaria hacemos que hable el espíritu de una raza con infinitas variaciones, buscando entender, interpretar y transmitir las voces de otras razas, lenguas y culturas. Lo primero que exige nuestro oficio es acercarnos a aquellas voces ajenas con una apertura

* Conferencia magistral dictada en ocasión de la celebración de los ochenta años de la Facultad de Filosofía y Letras de la UNAM, 1924-2004.

${ }^{1}$ Reproducido en la Gaceta de la UNAM, núm. 3,719, 17 de mayo de 2004. 
total hacia ellas, sin prejuicios ni discriminación, para comparar sus manifestaciones literarias con las de este país, difundirlas, y con este acto enriquecer las letras y el espíritu propios. Al proceder así en el campo de las letras alemanas, descubro muchas coincidencias en el fondo histórico e ideológico de la cultura mexicana y la alemana, fondo que, sin embargo, en un momento determinado mostró notables divergencias.

A partir de la creación del lema universitario, sin duda alguna se ha hecho un notable esfuerzo por superar la discriminación racial dentro de México, por lo menos en el ámbito del quehacer universitario. En el momento de establecerse nuestra Facultad en 1924, este esfuerzo ya estaba encaminado, y siendo la Universidad Nacional el centro preeminente de la enseñanza superior, se generalizó este afán por integrar a todos en su labor, independientemente del matiz que ostentaba la epidermis o el adorno capilar del individuo. Hoy, ochenta años después, no podemos afirmar que se hayan superado totalmente posiciones arraigadas, heredadas de la Colonia, pero el esfuerzo no ha quedado sin frutos.

En aquel año de 1924, en Alemania se inicia precisamente una corriente contraria a este afán universalista en México. Por medio de virulentas arengas que se extendían hasta las universidades, se incitó a una guerra santa de discriminación que habría de culminar en un genocidio, una vez que sus instigadores se habían instalado en el gobierno. El conglomerado de ideas y medidas aplicadas acabarían en una docena de años con el acervo espiritual y material de toda una cultura.

Los ciudadanos iluminados que se opusieron al surgimiento del fascismo con su vertiente de racismo en Alemania fueron legión; desgraciadamente, por razones que se han estudiado a fondo, éstos no alcanzaron a ofrecer la resistencia organizada que era necesaria para impedir la llegada de Hitler al poder. La política anunciada por el Partido Nacionalsocialista incluía el antisemitismo y el uso ilimitado de la violencia contra sus opositores. Esto significaba que los judíos tenían que abandonar el país. Los intelectuales, por su propia naturaleza no muy hábiles en el uso de armas, no iban a ejercer la violencia en su defensa, aunque en contados casos, sí lo intentaron. Independientemente de que en México el antisemitismo no ha muerto y la violencia hace estragos a diario en hogares, cantinas, en las calles citadinas y en la sierra y los pueblos, jamás se elevaron a ley suprema del país, y menos en las instituciones de enseñanza, lo cual sí ocurrió durante los años del fascismo en Alemania. Las señales de lo que iba a sobrevenir fueron percibidas claramente por mentes lúcidas como la de Ernst Bloch, quien escribió en 1924 un brillante ensayo sobre la violencia de Hitler (Bloch, 1924: 19-23), en el que llama a no subestimar a este adversario, ni, sobre todo, la influencia que ejerce en los grupos juveniles. Sin querer emitir a la ligera un juicio antropológico en cuanto al grado de inclinación a la crueldad por edades, se impone el patente hecho de la efectividad de indoctrinación en los jóvenes. 
Viene a la mente un testimonio que aduce Daniel Jonah Goldhagen en su obra Hitler's Willing Executioners, del cual se desprende que los miembros jóvenes de la ss ejercían con mayor saña la brutalidad contra sus víctimas en un campo de exterminio que los guardias de edad avanzada que no habían sido sujetos a la misma indoctrinación que la generación que creció bajo el fascismo (Goldhagen, 1996: 361).

Otro factor incisivo para el destino de la intelectualidad alemana fue la muerte de Lenin el 21 de enero de 1924. De hecho, Lenin ya habia languidecido durante meses antes de su muerte, y Stalin, previendo el desenlace fatal, tuvo amplio tiempo para preparar su complot para concentrar todo el poder en sus manos. Sólo un pequeño porcentaje de los escritores alemanes se había unido al Partido Comunista Alemán, cuya fundación se formalizó en los primeros días de 1919. La gran mayoría discutía aspectos teóricos y prácticos de las diferentes vertientes izquierdistas y ponderaba la posibilidad de afiliarse al Partido Comunista Alemán, empero, sin hacerlo. La mayoría simpatizaba con la izquierda, algunos participaban en acciones de militancia, por ejemplo en la lucha por el establecimiento de los Consejos Revolucionarios de Trabajadores y Soldados en noviembre de 1919. Esto no quiere decir que reinara claridad o unanimidad ideológica entre ellos. Pero en general, Lenin y sus enseñanzas gozaban de gran estima entre los intelectuales europeos de habla alemana. Debido a la supresión sistemática del pensamiento libertario en Alemania a lo largo de todo el siglo XIX y principios del XX, el pensamiento político y económico mostraba un gran rezago aún entre escritores y actores políticos. La sola lectura de la primera parte ensayística de la obra de Traven, País de la primavera, es una muestra del grado de confusión al cual un escritor puede llegar, a pesar de su producción de obras válidas en el aspecto histórico y social, y de su valor literario. Esto parece contradictorio, pero el escritor no necesariamente es un filósofo, economista o politólogo.

La figura de Lenin, incluso, aparece en algunas obras, por ejemplo en la de Alfred Döblin, llamada Noviembre de 1918. En 1924 este autor perteneció a la "Sociedad de los amigos de la nueva Rusia" (Gesellschaft der Freunde des neuen Russland). Hoy, Döblin es recordado por su novela Berlin, Alexanderplatz, publicada en 1929. Presenta un fascinante kaleidoscopio de aquella ciudad que inspiró a Rainer Werner Fassbinder a su opus filmico de ocho horas y media. Döblin aplica diversas técnicas narrativas, en las que el narrador cambia su función a veces dentro de un mismo párrafo y utiliza de repente el caló de los protagonistas de los bajos fondos de la gran ciudad. El autor permite que se independicen los protagonistas por medio del monólogo interior, presentando la psique compleja de alguna prostituta o criminal irredento. Döblin abre ante los ojos del lector cuadros sociales que nadie se había atrevido a incluir en sus obras 
literarias. Como médico con estudios en neurología y psicología, sus prolongadas actividades profesionales en hospitales y una institución mental, y como médico militar durante la Primera Guerra Mundial, tuvo acceso a las profundidades humanas - casi siempre trágicas- que forman la materia de esta obra.

La traducción de Berlin Alexanderplatz al castellano presenta enormes dificultades. La traslación del dialecto berlinés y las frecuentes inclusiones de versos de canciones populares o giros conocidos sólo a germanohablantes para trazar una emoción o el ambiente de un lugar, ofrece obstáculos casi insuperables para un traductor. Tal vez la cinematografía sea el medio para romper este tipo de barreras lingüísticas.

El día después del incendio del Reichstag, Alfred Döblin huyó con su familia a Zurich, luego a París, para finalmente encontrar asilo en Estados Unidos. Sus libros acabaron prohibidos y quemados en la pira del 10 de mayo de 1933, menos su Wallenstein, drama basado en la vida de uno de los estrategas de la Guerra de los Treinta Años (1616-1648). Independientemente del contenido de sus libros, siendo judío, tuvo que salir del país. Regresó a Alemania en 1945, sólo para salir del país nuevamente algunos años después, decepcionado por el giro político que estaba tomando la joven República Federal Alemana.

Las consecuencias de la muerte del dirigente bolchevique en 1924 se hacían sentir en muchos ámbitos. Sin saber qué habría pasado si la vida de Lenin y sus medidas políticas hubiesen continuado, sí se sabe lo que sobrevino: el estalinismo. El desencanto por la Unión Soviética cundía paulatinamente entre los escritores alemanes. Sólo un número relativamente pequeño escogió la Unión Soviética como país de asilo, y muchos aspirantes no fueron admitidos en ella. Casi todos los artistas y escritores que obtuvieron el permiso de ingresar a la Unión Soviética, por ejemplo, los miembros del Partido Comunista Alemán, perecieron en el Gulag. Stalin temía al Partido Comunista Alemán. El ex seminarista georgiano albergaba un fuerte resentimiento y una perenne suspicacia contra los comunistas alemanes, siendo ellos hijos de una nación industrializada y desarrollada. Entre la GESTAPO y la GPU se realizó un trabajo efectivo y radical en la liquidación de la inteligentsia izquierdista alemana y austriaca.

Para los simpatizantes del marxismo y los miembros del Partido Comunista Alemán —en cuanto lograron sobrevivir- empezó un calvario de conciencia. Esto lo podemos ver de cerca, por ejemplo, estudiando los diarios y las autobiografias de los escritores que vivieron en el exilio en México. Renunciar a sus ideales y su membresía en el Partido equivalía a una traición y a la aceptación del hecho de que este mundo no tenía salvación. Por otro lado, tampoco fue humanamente posible continuar en un movimiento cuyos líderes habían escenificado los procesos de Moscú a partir de 1934, que había hecho desaparecer a los comunistas alemanes y austriacos asilados en la URSS y luego asesinado 
a innumerables combatientes republicanos en la Guerra civil española. Si antes había discusiones amistosas entre los comunistas, ahora cualquiera de las posiciones implicaba perder amigos, crear enemistados - lo cual era de especial gravedad en una situación de asilo-, y el peligro de ser alcanzado por el largo brazo de Stalin, tal como lo ejemplifica el caso de Leon Trotski. Sin duda alguna, la producción literaria fue afectada gravemente, no sólo por vivir en un país de lengua diferente con pocas o nulas posibilidades de publicar y ser leído, sino también por el miedo y la creciente angustia. Los grandes disidentes surgen en diferentes rincones del mundo: Arthur Koestler, Steven Spender, Manès Sperber, Louis Fischer. En México, vegetan en una situación de ostracismo los escritores Gustav Regler, Otto Rühle, Alice Rühle-Gerstel y la pintora Marie-Luise Vogeler, esposa de Gustav Regler, hija del pintor alemán Heinrich Vogeler, ferviente admirador de la joven Unión Soviética, también desaparecido en el Gulag. Franz Pfemfert, quien había dirigido una revista izquierdista en Alemania, significativamente llamada Aktion, se retiró de toda actividad política y de sus antiguos compañeros en armas y fundó un pequeño comercio de artículos fotográficos en la colonia Roma. Dos fotógrafos, Walter Reuter y Hans Gutmann, alias Juan Guzmán, igualmente evitaron cualquier contacto que pudiera hacer recordar su pasado político, incluso el de la Guerra civil española, y se dedicaron a sus actividades fotográficas, documentando múltiples aspectos de su nueva patria, México. B. Traven, debido probablemente a sus inclinaciones anarquistas, detectó muy temprano el giro funesto que estaban tomando las cosas en la Unión Soviética, cuya proclama de fundación había saludado con entusiasmo en el número de noviembre de 1918 de su publicación Der Ziegelbrenner (El trabajador de la ladrillera). Un año más tarde Traven expresa en la misma publicación su temor de que el Partido Comunista Alemán, una vez llegado al poder, podría perseguir a sus oponentes. Y en $E l$ barco de la muerte hace declarar a uno de los protagonistas que los comunistas de aquellos días, o sea del año de 1926, siendo antes perseguidos, ahora se han convertido en los perseguidores más brutales (citado por Lübbe, 1989: 43).

Numerosos autores que no alcanzaron la fama de los grandes se deprimieron, dejaron de escribir, cayeron en el alcoholismo, en el cinismo, o incluso se suicidaron ante el giro que estaba tomando la política en la Unión Soviética, en cuya fundación habían fincado sus esperanzas para un mundo mejor. Desde su envidiable perspectiva de un sabio historiador y una edad que pocos hombres alcanzan, además de una visión multicultural que casi iguala la de un Elías Canetti, Eric Hobsbawm confiesa con cierto humor cómo superó esta decepción de una manera que le permitió seguir viviendo sin ser afectado demasiado: 
Llegué a Berlín a finales del verano de 1931, cuando la economía mundial se hundió. [...] Los meses de estancia en Berlín hicieron de mí un comunista para toda la vida, o, como mínimo, un hombre cuya vida perdería su carácter y su significado sin el proyecto político al que se consagró siendo estudiante, a pesar de que dicho proyecto ha fracasado de forma patente, $y$ de que, como ahora sé, estaba condenado a fracasar. El sueño de la Revolución de Octubre permanece todavía en algún rincón de mi interior, como si se tratara de uno de estos textos que han sido borrados : siguen esperando, perdidos en el disco duro de un ordenador, que algún experto los recupere (Hobsbawm, 2003: 54, 62).

Dispersos, algunos viviendo en la pobreza y la desesperación, se encuentran los grandes autores de los años veintes. El genial escenógrafo y director de teatro Max Reinhardt, quien había fundado su teatro en Viena precisamente en 1924 y quien estrenara posteriormente muchas de las más innovadoras obras del teatro en lengua alemana, trataba de ganarse la vida en Los Ángeles regenteando una academia para actores.

Dispersos también estaban los autores de esta brillante época del teatro y la narrativa en idioma alemán: Georg Kaiser salió en 1938 de Alemania y murió en 1945 en Suiza. Fue autor de obras del expresionsimo alemán que alcanzó fama en toda Europa en 1924 con el estreno de su comedia poco convencional Kolportage, basada en reportajes periodísticos. Bertolt Brecht había salido desde 1933 de Berlín y vagaba por Escandinavia hasta llegar vía Vladivostok al continente americano, "cambiando los países con más frecuencia que los zapatos” (Brecht, 1975: 320). El médico vienés Arthur Schnitzler, autor de la novela breve Señorita Elsa, obra maestra del monólogo interior, publicada en 1924, tuvo el tino de morir en 1931. El novelista praguense Franz Werfel ya había obtenido fama y grandes ediciones con su poesía y su narrativa. En 1924 publicó su drama Juárez y Maximiliano. Encontró asilo en Estados Unidos, donde murió en agosto de 1945. Después de la Segunda Guerra Mundial sus obras volvieron a editarse en Alemania con notable éxito. En Praga, Franz Werfel había conocido a Max Brod y Franz Kafka. En Viena, durante la Primera Guerra Mundial, tuvo estrecho contacto con Robert Musil. Sin embargo, en sus extensas novelas trata temas completamente diferentes de los de Kafka o Musil. Indaga en la posibilidad de amalgamar el judaísmo con el cristianismo. Después de su experiencia en el frente de Galitzia Oriental entre 1915 y 1917 , forma una sociedad secreta contra el militarismo con algunos de los futuros protagonistas de la Revolución de 1918, en la cual también participó. O sea, aparte de cavilaciones religiosas, vivía activa y conscientemente su tiempo.

Sigmund Freud vio en 1924 el inicio de la edición de sus obras en doce volúmenes, que llegó a su fin en 1939. El impacto de sus enseñanzas en el mundo 
artístico de su época es inconmensurable. Thomas Mann dictó una conferencia con el tema "La posición de Freud en la historia moderna de la cultura" en la Universidad de Munich en 1929, y tres años más tarde visitaría al padre del psicoanálisis en Viena.

En 1924 se publica La montaña mágica (Der Zauberberg) de Thomas Mann. El crítico literario Georg Lukács (1885-1971) es uno de los protagonistas, "Naphta". El dramaturgo Gerhart Hauptmann inspira la figura de Peeperkorn. Ambos personajes no sólo son protagonistas en la novela, sino durante largos años del siglo XX publican incesantemente sus obras: uno, sus ensayos, el otro sus obras dramáticas. Cabe mencionar que Gerhart Hauptmann, este prolífico dramaturgo de larga vida y Premio Nobel, nunca salió de la Alemania fascista. Es ínfimo el número de escritores que se quedara en Alemania durante el reino del fascismo.

El año de 1924, punto de partida de esta exposición, no puede verse aisladamente. Le anteceden años fatales, y 1924 no será el fin de la serie. Reinaban el hambre y la miseria en la mayor parte de la población, lo cual condujo a la publicación de la obra Die Kinderhölle in Berlín (Berlín, el infierno de los niños). El autor, Harry Graf Kessler, describe así la situación alimenticia:

En la mañana para niños y adultos una, o si las condiciones lo permiten, dos rebanadas de pan seco, o en los casos de los mejor situados, con un poco de mermelada o margarina. Esto se complementa con un sustituto de café. A mediodía en el trabajo [iel autor habla de los que aún tienen empleo!], otra vez una o dos rebanadas, en el mejor de los casos con margarina. En la noche, papas, col blanca o zanahorias. Carne sólo para los pudientes, y si mucho, una vez a la semana. Si no fuera por la comida donada por los cuáqueros, [...] crecería toda una generación de niños que para su sustento o disfrute no habrían comido otra cosa que pan seco, sustituto de café y verdura aguada (Kessler, 1988: 347). ${ }^{2}$

Es un pequeño consuelo saber que a raíz de esta publicación del Conde Kessler se inició una colecta internacional en favor de los niños alemanes. Kurt Tucholsky, un escritor más dado a la sátira que al lamento, apoya el llamado a la colecta con un artículo periodístico que cierra diciendo: "siete, diez, trece seres humanos duermen en un lugar, en el cual ningún campesino metería a sus animales [...] los niños afortunados mueren. Los demás actúan como si estuvieran vivos" (Kessler, 1988: 377). La situación iba a empeorar aún más.

En 1922 se había desatado con brutal fuerza la inflación. En el mismo año

${ }^{2}$ Trad. de la autora. 
ocurrió el asesinato de Walther Rathenau, el secretario de Relaciones Exteriores de la República de Weimar, perpetrado por extremistas de derecha después de firmar el tratado germano-soviético de Rapallo (Kessler, 1988: 382). Hoy nadie lo recuerda, ya que la historia tiende a recordar las fechas que desatan violencia y no las que tratan de conciliar intereses opuestos como fue el caso con este tratado.

Las camisas pardas estaban sembrando el terror en las calles de Munich, donde vivían Thomas y Heinrich Mann, además de un gran número de otros artistas. En 1926, los dos hermanos participan en una manifestación "contra la reacción muniquense". Para Thomas Mann esto significó un largo camino desde sus "Consideraciones de un apolítico", redactadas durante la Primera Guerra Mundial. Las opiniones apolíticas expresadas en aquel escrito fueron la causa del severo distanciamiento entre los dos hermanos que duró precisamente hasta que Thomas Mann decidió ya no cegarse ante las molestas realidades de la vida pública. En 1929 recibe el Premio Nobel que acepta "como símbolo de la simpatía mundial hacia su pueblo", o sea, hacia el pueblo alemán, del cual pocos años después Bertolt Brecht tiene que lamentarse en este poema:

Deutschland

Mögen andere von ihrer Schande sprechen, Que otros hablen de su oprobio, ich spreche von der meinen.

O Deutschland, bleiche Mutter!

Wie sitzest du besudelt

Unter den Völkern.

Unter den Befleckten

Fällst Du auf.

$[\ldots]$

In deinem Hause

Wird laut gebrüllt, was Lüge ist

Aber die Wahrheit

Muss schweigen.

Ist es so?

Warum preisen dich ringsum die Unterdrücker, aber

Die Unterdrückten beschuldigen dich?
Alemania yo hablo del mío.

Oh, Alemania, ¡madre lívida! Cómo te encuentras entre los pueblos tan mancillada. Entre los manchados Llamas la atención.<smiles>[AlH]</smiles>

En tu casa a gritos se dicen mentiras. Pero la verdad tiene que callarse. ¿No es así?

¿Por qué te alaban los opresores por dondequier, pero los oprimidos te acusan? 
Die Ausgebeuteten

Zeigen mit dem Finger auf dich, aber

Die Ausbeuter loben das System

Das in deinem Hause ersonnen wurde!

$[\ldots]$

O Deutschland, bleiche Mutter!

Wie haben deine Söhne dich zugerichtet

Dass du unter den Völkern sitzest

Ein Gespött oder eine Furcht!
Los explotados

te señalan con el dedo, ipero los explotadores alaban el sistema que fue ideado en tu casa!

(Brecht, 1975:-186-87).

Oh, Alemania, ¡madre lívida! ¿Qué han hecho de ti tus hijos, de manera que ocupas un lugar de escarnio o de miedo entre los pueblos! ${ }^{3}$

En efecto, todavía durante los años veintes, los ojos del mundo occidental estaban dirigidos con simpatía, admiración y sed de conocimiento hacia Alemania, tal y como lo expresó Thomas Mann. El mundo universitario europeo observaba con interés las actividades y publicaciones del Instituto de Investigación Social de Francfort (Frankfurter Institut für Sozialforschung) que funcionaba desde 1923. Gracias a su buena reputación, los escritores, artistas y pensadores alemanes obtuvieron visados para Estados Unidos y para México, entre algunos países más, cuando ya tuvieran que huir. Esto facilitó cierta continuación de su labor intelectual. Así, por ejemplo, el mencionado Instituto fue trasladado a Génova en enero de 1933, y un año después a Nueva York, donde bajo el nombre de International Institute of Social Research se asoció a la Universidad de Columbia. Incluso, algunos de sus colaboradores llegaron a México, por ejemplo el psicoanalista Erich Fromm, quien se asentó en Cuernavaca. El filósofo Herbert Marcuse (1898-1979) fue huésped en México, y en esta Facultad dictó una conferencia ante un público entusiasmado con el movimiento estudiantil de 1968.

El director del Instituto de Investigación Social de Francfort fue el filósofo Max Horkheimer, y Theodor Adorno uno de sus más cercanos colaboradores. Había brillantes exponentes de nuevas líneas de investigación sobre la sociología de la música y de la literatura, o sea, novedosas aplicaciones del pensamiento filosófico. La idea básica fue que únicamente el estudio en conjunto de las diversas disciplinas del quehacer humano podria conducir a conclusiones válidas sobre la sociedad humana, y que uno de los resultados podría ser que

\footnotetext{
${ }^{3}$ Trad. de la autora.
} 
los integrantes de una sociedad obtuvieran claridad sobre el estado de cosas en ella. La base fue una discusión libre y científica sobre las diversas cuestiones sociales. Obviamente, la libre discusión constituía un peligro para el nuevo gobierno. En marzo de 1933, un cateo en el Instituto trajo a luz un cúmulo de "escritos subversivos", se cerró el Instituto y sus bienes disponibles (los demás ya se encontraban fuera del país) fueron confiscados en beneficio de la provincia de Prusia. Casi todos los académicos del Instituto lograron encontrar asilo en el extranjero y reunirse de nuevo en el exilio. Así se formó en Francia L'Institut des Recherches Sociales y en Estados Unidos The New School for Social Research, el cual se anexó a la Universidad de Columbia con el nombre de Institute for Social Research.

Los artículos de los críticos literarios y de los comentaristas en los importantes diarios y semanarios alemanes fueron leídos en toda Europa. En 1924 Siegfried Kracauer llegó a ser redactor en jefe de la importante Frankfurter Zeitung. Además es autor de varias novelas con una aguda crítica social y con un mensaje pacifista. A partir de 1930, Kracauer trabajaba en Berlín, ciudad que junto con Munich formaba el centro de la vida literaria y cultural de entonces. Reseñaba las obras de los grandes escritores de su tiempo, incluyendo las de Kafka, y observaba atentamente la boyante producción cinematográfica. Todavía se consulta su obra fundamental sobre este tema: Von Caligari zu Hitler. Ein Beitrag zur Geschichte des Films (De Caligari a Hitler. Una aportación a la historia del cine), reeditada por la editorial Rororo en 1958. También Siegfried Kracauer tuvo que abandonar Alemania en 1933. Murió en Nueva York en 1966.

De Joseph Roth (1894-1939), en 1924 ya se habían publicado sus novelas Hotel Savoy y Die Rebellion (Hotel Saboya y La rebelión). Tratan la problemática de los soldados que regresan de la guerra. De manera que estas novelas pueden incluirse en la categoría de las novelas pacifistas que abundaban durante la República de Weimar, las cuales finalmente no cumplieron su cometido de evitar una nueva guerra.

Joseph Roth era un autor conocido en Alemania y en Austria cuando tuvo que huir a Francia. Una parte de la vida literaria en idioma alemán se trasladó a París, sin poder compararse en dimensión y alcance con su anterior posición en Berlín, Munich, Viena y Praga. Su estancia en París permitió a este autor continuar su obra y su existencia, aunque fuera en condiciones precarias, y sólo durante pocos años. Esto no fue dado a los que no lograron huir a tiempo. Así pasó con uno de los personajes más creativos y rebeldes en el escenario literario, periodístico, incluso cabaretístico, Erich Mühsam (1878-1933). Igual que Karl Kraus, editó una revista con textos exclusivamente de su propia autoría. Incansablemente escribió y organizó grupos contra los fascistas, y, por supuesto, fue miembro activo de los Consejos Revolucionarios en Munich. A raíz de ello, fue 
juzgado y para su gran sorpresa no condenado a muerte sino a quince años de prisión para presos políticos, de los cuales tuvo que purgar cinco. En 1924 fue liberado, en el mismo año en que Hitler fue condenado por su golpe de estado a sólo cinco años de prisión, y liberado después de ocho meses. El fatídico 28 de febrero de 1933, Erich Mühsam fue arrestado por los nazis y después de poco tiempo sucumbió a los maltratos que sufrió.

Uno de los integrantes de los Consejos Revolucionarios que sobrevivió la masiva represión que los aniquiló, fue B. Traven. Es precisamente en el verano de 1924 cuando se da este curioso encuentro entre el mundo literario alemán y México: B. Traven desembarca en las costas del golfo de México, después de haber sido expulsado de Inglaterra. Según algunos indicios la causa de la expulsión fue que desde su llegada a Inglaterra en 1923 dio a escoger entre seis diferentes identidades, lo cual no fue del agrado de las autoridades británicas (Machinek, 1989: 79). Después le fue negada la entrada a Estados Unidos, posiblemente porque su pasado, la participación en la revolución socialistaanarquista de Munich de 1918-1919, lo alcanzó. En su diario apunta el 26 de julio de 1924 que "el bávaro de Munich ha muerto" (Machinek, 1989: 79) y nació $B$. Traven, Torsvan Torsvan, Hal Croves y otros alias bajo los cuales vive, escribe, se casa y muere en México en marzo de 1969 a la edad de... no sabemos a ciencia cierta qué edad, ya que el 25 de febrero de 1882 y el 3 de mayo de 1890 son las fechas de nacimiento entre las que este misterioso autor da a escoger a los que buscan desentrañar su vida. A partir de 1925, Traven publica en la recién fundada editorial popular alemana, la Büchergilde Gutenberg, en rápida secuencia sus novelas Los pizcadores de algodón, El barco de la muerte y El tesoro de la Sierra Madre, en alemán. De hecho, la secuencia de sus publicaciones es tan veloz que existen serias dudas acerca de la autoría única de Traven. Un ejemplo: en los años setentas apareció la viuda de un marinero ruso, supuesto autor del manuscrito original de El barco de la muerte.

El joven Bertolt Brecht, nacido el 10 de febrero de 1898 en Augsburg, muerto en Berlín, en la República Democrática Alemana, el 14 de agosto de 1956, desde muy joven formó parte del gran surgimiento de las letras y las artes de su tiempo. En noviembre de 1922 recibió el premio Heinrich von Kleist, y a partir de 1920 era miembro de la Unión de los Escritores y Músicos para el Teatro (Verband Deutscher Bühnenschriftsteller und Bühnenkomponisten). En 1923 el entonces ya famoso novelista Lion Feuchtwanger, colaboró con él para preparar la presentación escénica en idioma alemán de la obra de Christopher Marlowe Edward II. Esta versión de Brecht/Feuchtwanger, que fue estrenada en 1924 en el Teatro de Munich (Münchner Kammerspiele), significativamente trata del uso y del abuso del poder.

Brecht ya había obtenido éxito en 1922 con la obra Trommeln in der Nacht 
(Tambores en la noche) y en 1923 con Im Dickicht der Städte (En la jungla de las ciudades), presentadas ambas en Munich. Estos éxitos lo animaron a trasladarse de Munich a Berlín en 1924, al centro neurálgico de la vida literaria y teatral del momento. No todos los críticos aplaudian sus obras que ostentaban novedosas escenografias y su particular "efecto de extrañamiento". En Berlín trabajó luego para terminar la obra Mann ist Mann (Un hombre es cualquier hombre). Esta obra muestra una analogía temática con los escritos de Kafka: la deshumanización del individuo, su falta de autonomía, su reducción a un número y a un instrumento para fines que otros dictan, resultando con esto su absoluta sustituibilidad. Cualquier hombre puede servir a los mismos fines que otro, todos pueden ser instrumentalizados, intercambiados sin concederles el derecho a una identidad propia. Lo curioso es que cuando Brecht inicia un estudio sistemático de El capital en 1927, dice: "Cuando leí El capital de Marx, entendí mis obras. Se comprende que me gustaría ver una amplia difusión de esta obra" (Hecht, 1978: 77).

Como ya se ha dicho, los intelectuales y artistas simpatizaban con el comunismo, se ocupaban de él, lo discutían, pero pocos entraron en el Partido Comunista Alemán. Un comentarista que conoce tanto a Brecht como a Walter Benjamin, resume así la posición de ambos: "Las conversaciones entre los dos hombres [...] muestran dudas, no en cuanto al marxismo, sino sobre la praxis del marxismo: Brecht se opone condicionalmente a Stalin, Benjamin apoya condicionalmente a Trotski" (Kraft, 1972: 69).

Cuando se estaba volviendo más y más tensa la atmósfera en Alemania por la incrementada actividad de las camisas pardas contra los izquierdistas y los judíos según lo anunciado en la obra Mi lucha, escrita también en el ominoso año de 1924, éstos empezaron a buscar otros sitios donde continuar su vida. Para ellos surgió la alternativa Moscú o Jerusalén. El llamado de Theodor Herzl de emigrar a Palestina se había difundido ampliamente. Al mismo tiempo sonaban los llamados de acudir en ayuda del pueblo ruso para participar en la construcción de la joven Unión Soviética. Un buen amigo de Walter Benjamin, Gershom Sholem, invitó insistentemente a aquél a reunirse con él en Palestina. Walter Benjamin anunció telegráficamente tres veces su llegada, y nunca emprendió el viaje. En 1924 una amiga muy querida por Benjamin, la letona Asja Lacis, también asistente escénica de Brecht (Tiedemann, 1900: 161), decretó para Benjamin: "El camino de una persona progresista conduce a Moscú, no a Palestina" (Unseld, 1972: 9). Entre la alternativa entre Moscú y Jerusalén, él no escogió ninguna, sino buscó otra salida, la muerte, el 26 de septiembre de 1940. Un amigo suyo, Werner Kraft, resume así las circunstancias del fin de Walter Benjamin: 
Las autoridades francesas no conceden a los emigrantes judíos visados de salida. Por ende, cruzan ilegalmente la frontera a España [para llegar a Lisboa de donde zarpan los barcos hacia el continente americano]. El grupito arribó al pueblo español fronterizo [Portbou] y se les informó que el ingreso era prohibido para judíos; tendrían que regresarse. Esto significó campo de concentración. Benjamin perdió los nervios y tomó morfina. [...] Murió. La siguiente mañana todo resultó diferente. Los oficiales habian mentido. Querían dinero. Todos pudieron quedarse en España. Benjamin tenía suficiente dinero. En América todo estaba preparado para él (Kahmen, 1992: 54). ${ }^{4}$

Los antropólogos afirman que un ser humano no resiste varios "ritos de paso" en una sola vida para construir cada vez una nueva identidad. Posiblemente esto sea aplicable a Walter Benjamin. Él mismo lo expresa en un curriculum vitae, en el que solicita ayuda a una asociación danesa para escritores desterrados:

En marzo de 1933 yo, ciudadano alemán, tuve que abandonar Alemania a la edad de casi 41 años cumplidos. Debido a la transformación política no sólo perdí de golpe mi base existencial como investigador y escritor independiente, sino también mi libertad personal corría peligro a pesar de no pertenecer a ningún partido político y siendo disidente. Mi hermano fue aprehendido en el mismo mes y maltratado severamente. Hasta Navidad continuó en un campo de concentración.

De Alemania me dirigí a Francia, ya que a raiz de mis trabajos previos esperaba encontrar ahí un campo de trabajo. [...] Desgraciadamente no se cumplieron mis esperanzas de establecer una nueva existencia independiente en París. [...] En Dinamarca encontré albergue provisional en la casa de la familia Brecht. Puedo aceptar su hospitalidad sólo por corto tiempo. Por el otro lado, carezco totalmente de reservas financieras. Mi única posesión es una pequeña biblioteca de trabajo que pudo instalarse en la casa del señor Brecht (Unseld, 1972: 48, 50, 51). ${ }^{5}$

Cabe mencionar que la amiga de Walter Benjamin que había insistido en que él buscara refugio en Moscú, pasó diez años de su vida en el Gulag, de 1938 a 1948.

El 3 de junio de 1924, en la entonces ya no tan grande Austria, murió Franz Kafka. Su problemática no fue la de Walter Benjamin. Aún no se percibía ni en Viena ni en Praga que Hitler y sus secuaces destruirían pocos años después varias grandes culturas, avanzando sobre campos sembrados con cadáveres,

${ }^{4}$ Trad. de la autora.

${ }^{5}$ Trad. de la autora. 
resultados del genocidio que perpetraban. A pesar de vivir entonces una existencia a primera vista menos angustiosa, Kafka veía los signos en la pared: el ocaso del ser humano, devorado por la burocracia y privado de su identidad. $Y$ Walter Benjamin fue uno de los que más se había preocupado por entender a este gran maestro innovador del idioma alemán y de visión profética.

Muchos son los motivos por los cuales las obras de Kafka encontraron poca difusión después de la Segunda Guerra Mundial, y prácticamente ninguna en el mundo socialista. Pero nos equivocamos si pensamos que antes de 1939 no hayan encontrado eco y análisis entre cierto público lector. Europa formaba una especie de Comunidad Europea Intelectual durante los años veintes y treintas del siglo pasado. Walter Benjamin tenía el plan de hacer un libro sobre "los tres grandes metafísicos entre los escritores del presente: Franz Kafka, James Joyce, Marcel Proust" (Benjamin, 1972: 47). No llegó a realizar este plan, lo cual es una gran pérdida para la literatura, ya que la extraordinaria agudeza de su espíritu crítico nos ha legado juicios reveladores sobre un gran número de obras literarias y cuestiones sociales y culturales. Aún durante la vida de Walter Benjamin, las visiones de Kafka sobre el rumbo que iba tomando la marcha de la humanidad, habrían de revelarse en la existencia misma de Benjamin.

Cuando los más excelsos representantes de la vida espiritual alemana se encontraban en deplorables condiciones de encierro en campos dispersos por toda Europa, se dio el momento de la revelación de la verdad de Kafka. El escritor Hans Sahl, uno de los compañeros del confinamiento de Benjamin en un campo en Francia, recuerda lo siguiente:

La incomparable capacidad de Benjamin de reconocer el todo a través del detalle, en esta ocasión se volvió contra él. Lo absurdo del detalle obstaculizaba la visión del todo, ya que los detalles se habían vuelto autónomos. [...] En el proceso de buscar orientarse en la realidad mediante su inteligencia, su comprensión histórica y política, se alejaba cada vez más de ella. Al considerar la realidad como tal, aceptándola literalmente, verbalmente, para desenmascararla, sólo desenmascaró la impotencia del verbo, el cual ya sólo fue usado como fachada por la realidad. [...] Como marxista, Benjamin creía poder cambiar la realidad. Por supuesto, esto fue imposible entonces (Sahl, 1972: 74-75). ${ }^{6}$

Kafka quería presentar exactamente esto, y fue capaz de hacerlo. Desde 1912 había intentado encontrar editores para sus obras en Leipzig y en Weimar, con resultados poco satisfactorios. El proceso, que ya había redactado diez años antes, fue publicado en 1925. "El fogonero", fragmento de América, apa-

\footnotetext{
${ }^{6}$ Trad. de la autora.
} 
reció en 1913, La metamorfosis en 1916. En 1923 se encontraba en Berlín, de manera que vio y percibió la situación en Europa no sólo desde Praga. Siente profundamente la crisis reinante, no alberga ilusión alguna sobre la humanidad, dominada por el burocratismo y el automatismo, destructores del individuo, y siente la tragedia de esto doblemente, porque sabe que no se trata de catástrofes naturales sino provocadas por el hombre mismo. En esta contradicción, las categorías de la causalidad, del espacio y del tiempo quedan abolidas. A Kafka no sólo le pesa su propia existencia, sino la de toda la humanidad. Tal vez la expresión más radical de esto son las narraciones "En la colonia penitenciaria", publicada en 1918, y "El artista del hambre", en 1924. En 1915 había recibido el Premio Theodor Fontane, nombrado así por el gran novelista prusiano de la segunda mitad del siglo XIX. Entre las interpretaciones más lúcidas que conozco sobre las obras de Kafka figura un ensayo de Günter Grass, "Kafka und seine Vollstrecker" ("Kafka y sus ejecutores"). Como poeta y crítico observador del devenir histórico, Grass es predestinado para comprender y explicar a Kafka. Una de sus frases en este ensayo es: "Las obras literarias no siguen los ritos de la lógica sino las leyes de la estética" (Grass, 1980: 109).

Las obras de Kafka no fueron quemadas, ni por su amigo Max Brod, a quien se lo había pedido, ni tampoco por los nazis. No las habían leído, seguramente, y si acaso, no las tomaron en cuenta en su verdad y advertencia. En el mundo socialista, la lectura de Kafka estaba vedada, y si en alguna universidad se interpretaban sus escritos, era en el sentido de que su crítica estaba dirigida únicamente contra los males del capitalismo.

Aquí en la Facultad de Filosofia y Letras, desde hace sesenta años, se analiza la literatura que es accesible a nosotros. La analizamos a diario en clase y en innumerables publicaciones, dedicándonos a ello en días hábiles y no hábiles. Las publicaciones de la Facultad invitan a profesores y alumnos a disfrutar y analizar críticamente los resultados de los desvelos académicos. No todos los juicios contenidos en ellas serán acertados. Son un estímulo para el pensamiento propio y para emprender más lecturas, agudizar la observación para la reflexión y también la acción. Por el momento, no existen listas negras ni líneas oficiales de interpretación en nuestra Facultad. Aprovechémoslo.

\section{Bibliografia}

BENJAMIN, Walter. 1972. "Drei Lebensläufe”. Zur Aktualität Walter Benjamins.

Ed. Siegfried UNSELD. Francfort/M.: Suhrkamp. 45-47.

BLOCH, Ernst. 1924. "Erinnerung: Hitlers Gewalt (1924)". Dort, wo man Bücher verbrennt. Ed. Klaus SCHÖFFLING. 1983. Francfort/M.: Suhrkamp, 19-23. 
BRECHT, Bertolt. 1975. "Lieder Gedichte Chöre. 1818-1933”. Gedichte. Ed. Werner MITTENZWEI. Berlín, Weimar: Aufbau. 186-187.

GOLDHAGEN, Daniel Jonah. 1996. Hitler’s Willing Executioners. Nueva York: Random House.

GRASS, Günter. 1980. "Kafka und seine Vollstrecker". Aufsätze zur Literatur. Darmstadt, Neuwied: Luchterhand. 99-121.

HECHT, Werner, ed. 1978. Bertolt Brecht. Sein Leben in Bildern und Texten. Berlín: Aufbau.

HOBSBAWM, Eric. 2003. Años interesantes. Una vida en el siglo XX. Barcelona: Crítica.

KAHMEN, Volker. 1992. "Walter Benjamin und Werner Kraft". Für Walter Benjamin. Ed. Ingrid y Konrad SCHEURMANN. Francfort/M.: Suhrkamp. 34-55.

KESSLER, Harry Graf. 1988. Tagebuch eines Weltmanns. Marbach: Deutsche Schillergesellschaft.

KRACAUER, Siegfried. 1958. Von Caligari zu Hitler. Ein Beitrag zur Geschichte des Films. Reinbek b. Hamburg: Rororo.

KRAFT, Werner. 1972. “Über Benjamin”. Zur Aktualität Walter Benjamins. Ed. Siegfried UNSELD. Francfort/M.: Suhrkamp. 59-69.

LüBBE, Peter. 1989. "B. Traven und der Kommunismus". Text + Kritik, núm. 102, abril. 43-49.

MACHINEK, Angelika. 1989. "Vita B. Traven". Text + Kritik, núm. 102, abril. 76-84.

SAHL, Hans. 1972. "Walter Benjamin im Lager". Zur Aktualität Walter Benjamins. Ed. Siegfried UNSELD. Francfort/M.: Suhrkamp. 74-81.

SCHOLEM, Gershom. 1987. Walter Benjamin. Historia de una amistad. Barcelona: Ediciones Península.

TIEDEMANN, Rolf, Christoph GÖDDE y Henri LoNITZ, eds. 1900. Walter Benjamin 1892-1940. Marbach: Deutsche Schillergesellschaft.

UNSELD, Siegfried, ed. 1972. Zur Aktualität Walter Benjamins. Francfort/M: Suhrkamp.

WITTE, Bernd. 1990. Walter Benjamin. Una biografia. Barcelona: Gedisa.

P. S. sobre Walter Benjamin: 
Bernd Witte, Walter Benjamin. Einführung in Leben und Werk. Rowohlt Monographien. und Rowohlt Taschenbuchverlag, Reinbek b. Hamburg, 1985. . Walter Benjamin. Una biografia. Barcelona, Gedisa, 1990.

Gershom Scholem: Walter Benjamin, die Geschichte einer Freundschaft. Fráncfort M., Suhrkamp, 1975.

. Walter Benjamín, Historia de una amistad. Barcelona, Ediciones Península, 1987. 